\title{
Traver Concept Plan: A Participatory Process
}

\section{VICENTE DEL RIO AND UMUT TOKER}

In the summer of 2006, faculty Vicente del Rio and Umut Toker developed a series of community workshops in Traver, Calif., towards a participatory concept plan envisioning local development and future growth. In this article they discuss the active involvement of the community and the successful results of this planning process.
Vicente del Rio, Ph.D., is a professor at Cal Poly's CRP Department.

Umut Toker, Ph.D., is an assistant professor at Poly's CRP Department.
Traver is a small community of around 180 families in Tulare County, along State Highway 90 in California. The closest cities to the north are Kingsburg, only seven miles away, and Fresno, which is at a short 20-minute drive. Visalia is about 21 miles south off of Route 198. Agriculture, a flouring mill and the railroad were responsible for making Traver a thriving town in the $1880 \mathrm{~s}$. Unfortunately, it only lasted until the end of the 19th century, when a series of devastating fires and a sudden increase in the alkali levels damaged the agricultural soil. Most of the population and businesses were scared out of Traver, and the community's development came to a grinding halt, until recently, despite the proximity to the highway and to larger towns (Figure 1).

In the beginning of 2006, Cal Poly's City and Regional Planning Department was contacted by George Nord, principal of Traver's Elementary School. Having served in the school district for many years and having developed a strong attachment to Traver, Nord is a community leader legitimately concerned about the future of the community. Besides Traver's evident need for better infrastructure and services, Nord feared that the town would eventually succumb to haphazard highway commercial development and to speculative housing due to the demand of the nearby cities and the Central Valley in general. Since he was familiar with the potential of good planning and with the community-outreach projects developed by the CRP Department, he contacted us to support his quest for a better future for Traver.

Faculty members Vicente del Rio and Umut Toker took

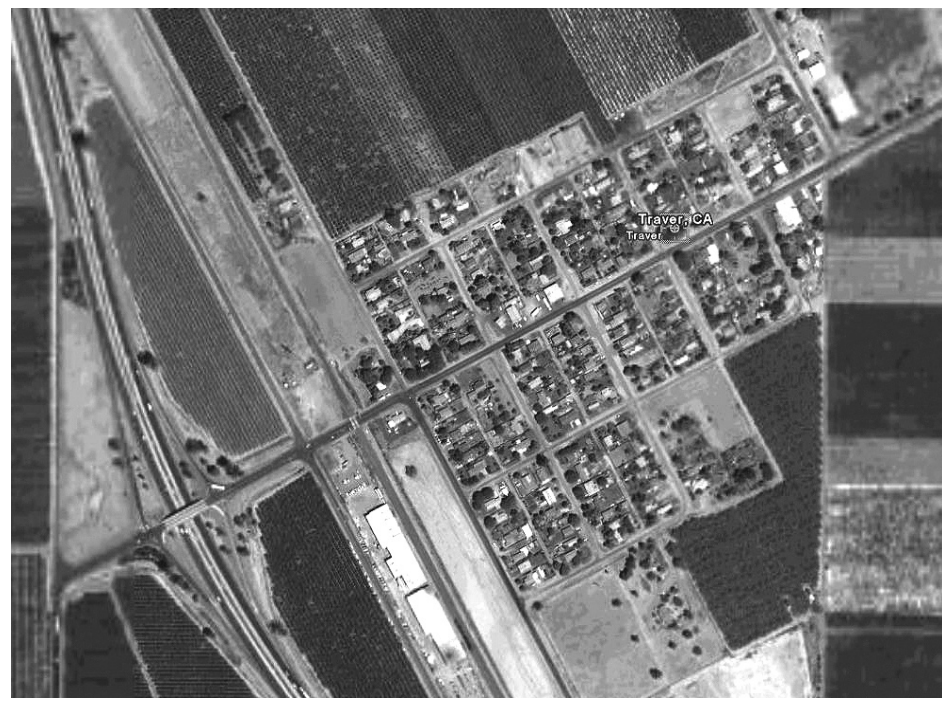
the task of helping the community and developed a plan through a participatory process during the summer of 2006. During the fall quarter, the third year class "Community Design Lab" (CRP 341) with instructor del Rio, went further and developed the Traver Urban Design Plan. ${ }^{1}$ With the strategic support of the County of Tulare's community development specialist Frank Ruiz - who acted as the liaison between the Traver community and the Cal Poly team - two contracts were signed between the county's Community Development and Redevelopment Department and Cal Poly Corporation.

\section{The Traver Concept Plan}

The Traver Concept Plan was developed through a participatory process based on the understanding that community involvement and participation in decision making is fundamental in planning and design. Community participation not only permits a better understanding of existing problems and

\section{Figure 1}

Aerial photo of Traver, showing State Highway 90 and the railroad tracks. Image from Google Earth.color) on the left, and California on the right.

\begin{abstract}
${ }^{1}$ See the article "Traver Urban Design Plan" by Michael Costa in this issue of FOCUS.
\end{abstract}


2 Student assistants: David Grim (BCRP program) during the whole process, and Alex Friedman and Joaquin Salazar (MCRP prgrams) in the first workshop. potentials, but it also guarantees representative and equitable decisions and proposals. In a small non-incorporated community such as Traver, with a long history of basic needs, participatory planning processes are ideal to empower citizens and make them aware of their own needs and potentials, to encourage stronger community representation, and to foster the involvement of the stakeholders in plan implementation and in other civic affairs.

The main goal of the Traver Concept Plan was to identify a vision for the future development of the community through a series of workshops with residents and community representatives. The process helped the community to understand their own strengths, weaknesses, constraints, and opportunities, as well as the importance of getting organized around a set of ideals and ideas to direct their own actions in the future. Pointing out directions for Traver's development, and identifying possible paths, agencies, and actors to carry them through were important outcomes of the participatory process. The process also empowered the community by making them aware of their own problems and potentials, by helping them to identify a set of legitimate demands organized in a plan of action.

\section{The Process}

From the start, the Cal Poly team, utilized participatory methods. Always with the assistance and support of school principal Nord and planner Ruiz, the Cal Poly team conducted a series of community workshops in the Traver elementary school. A total of five workshops were held, each holding between 20 to 30 participants. During the workshops the team ensured that all participants were given a voice and got involved in the decision making process. Spanish speaking members of the community were helped by the Cal Poly team and/or other community members.

A series of participatory and group dynamics methods were utilized during the workshops (Figure 2). Constraints, opportunities, qualities, and problems were identified; a set of goals, strategies, and actions were discussed and prioritized; and the final results were put together in a vision for Traver's future development. In all stages of the process, community members voiced their concerns, ideas and observations and were directly involved in decision making. The team acted not only as planners but as process designers and facilitators.

The objective of the first workshop was to identify the community's perceptions of Traver and its negative and positive attributes, as well as a vision for its future. Two instruments were specifically designed by the Cal Poly team for the focus group interviews and the vision exercise that composed this workshop. There were two major results: (1) a list of positive and negative aspects of Traver according to the community's perceptions - categorized into common themes - and, (2) a list of six goals for future development. In the second workshop, the community prioritized the goals identified previously and decided on the strategies to achieve them. Again, the Cal Poly team designed two instruments: the first enabled individual participants to prioritize the goals and to define three strategies for each goal, and the second facilitated the group to get to an agreement.

The third workshop was on action planning. Having identified a development vision, goals and strategies for Traver, the Cal Poly team designed a new exercise to allow participants to correspond the chosen strategies to action steps towards implementation, the person(s) to initiate each action, and the funding sources. With these results, the Cal Poly team identified a list of goals in order of priority, and strategies and action steps for implementing each of the strategies. By this time in the process, the Cal Poly team had already obtained incredibly rich information on the community's perceptions, expectations and willingness to set forth a process to direct future development actions in Traver. 
The forth community workshop was on concept planning, and it focused on issues directly related to physical and spatial solutions. For this workshop, the Cal Poly team analyzed data from the previous workshops and identified all the issues related to the built environment cited by the participants. These issues were organized into three categories: "areas" (including all ideas related to identifiable areas, such as land uses), "routes" (ideas related to lines, or identifiable routes, such as for public transportation), and "spots" (ideas related to specific locations, such as for a traffic light). Then, the Cal Poly team designed a three-step space planning exercise using a board game approach. ${ }^{3}$ During the workshop, participants were organized into small groups and encouraged to "spatialize" their specific ideas and proposals on base maps of Traver. They followed a legend representing specific items in the categories of "areas"

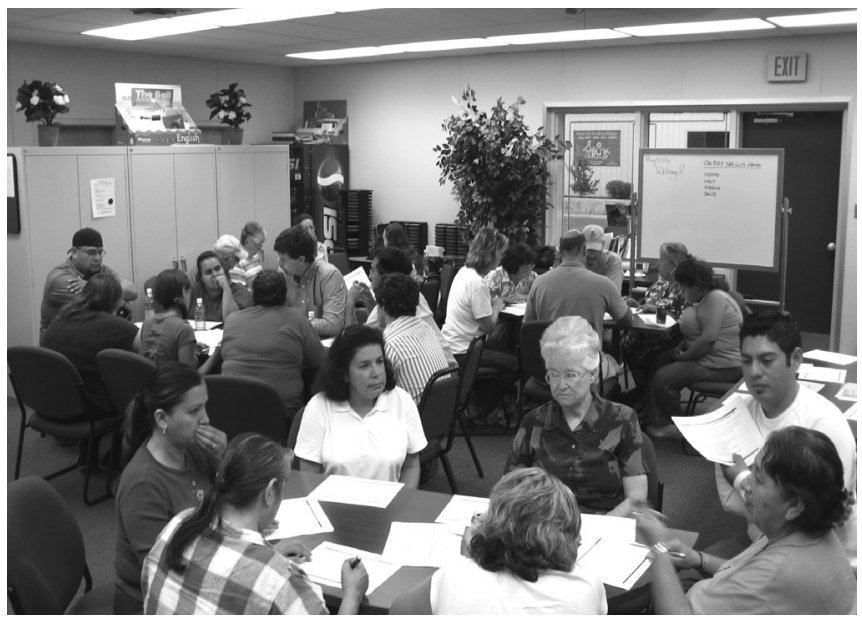

Figure 2

One of the workshops, when participants were working in small groups helped by students.

${ }^{3}$ Based on Sanoff, Henry. 2000. Community Participation Methods in Design and Planning. New York: J. Wiley. affordable housing), parks, slower traffic zones and traffic lights, the diversion of truck traffic from the community, a new bus line serving the community and the school, potential locations for a police station, a medical facility, and a community center. Participants also agreed on the need to provide Traver with an attractive identity, and on enhancing the quality of their main street.

The last workshop was a "celebration session" in which all the products and the concept plan were presented by the Cal Poly team to the community during a meal promoted in the Traver School. Representatives from the county's Community Development and Redevelopment agency and of the State Assembly were present, which helped support the plan making process and the results, and allowed the community to start a political process towards solving its concerns and implementing its own vision.

\section{The Products}

The participatory process allowed the Cal Poly team to assist the Traver community in developing a vision for the future and to identify development goals, an action plan and a physical concept plan based on the understanding of their needs, expectations, constraints and opportunities for development. While there are pressing needs for investment in basic infrastructure (namely storm water drainage, sewage disposal, street paving, and public lighting), better control of vehicular circulation (namely trucks), and an efficient alternative for public transportation, the community is aware of Traver's potential due to its good location and accessibility, and it is ready to participate in the building of its own future.

It is envisioned that the Tulare Concept Plan will support the updating of the existing community and redevelopment plans, as they both seem outdated and distanced from the local reality and 
community expectations. The concept plan recommends that support for new residential and highway commercial development in Traver be added into the on-going County General Plan update. The community is well aware of its potential for becoming a development hub in the Central Valley, particularly in serving the present housing demand, and that this growth should coincide with its vision of quality and in keeping Traver's "small town" appeal and agricultural image.

Finally, the concept plan recommended that Cal Poly's City and Regional Planning Department be contacted for further technical assistance, and that a class be asked to develop another planning step for Traver in the form of an urban design plan. This would help the community determine concrete physical solutions for future development, and would assist the Tulare County as a platform for a new redevelopment plan, and a set of guidelines to community-supported new development. In the fall quarter of 2006, a third-year undergraduate studio developed the Traver Urban Design Plan, a process described in the next article by Michael Costa.

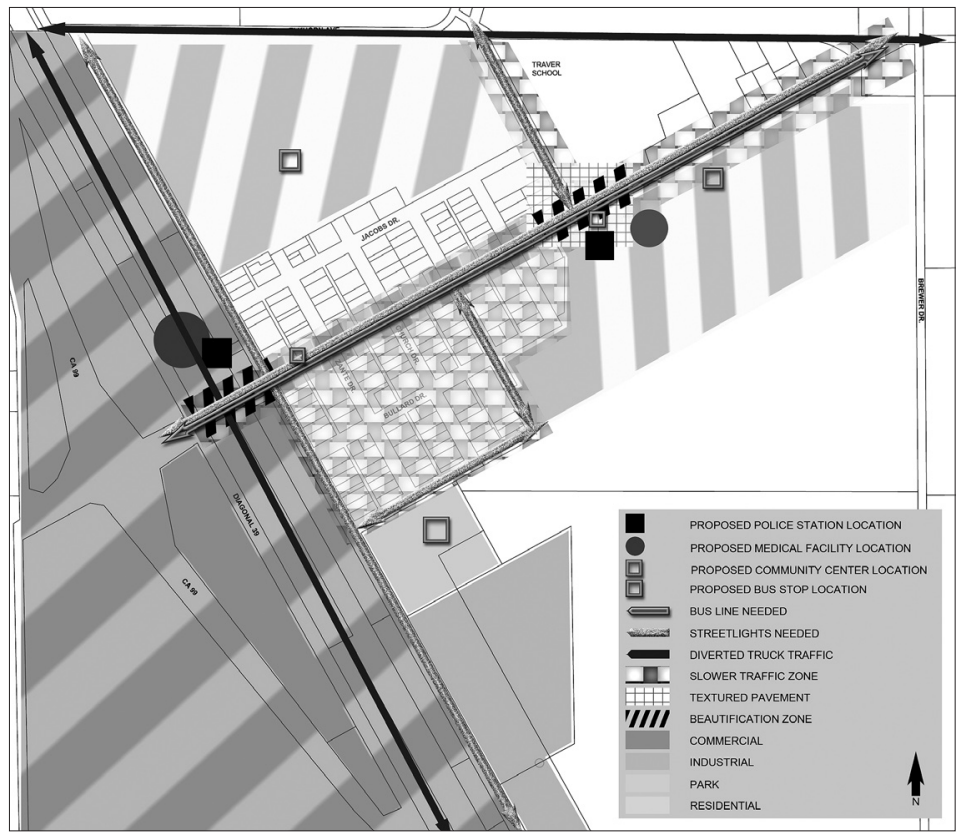

Figure 3

Final community concept plan (original in colors). 